\title{
Role of Life Table in Insect Pest Management--A Review
}

\author{
A. M. Kakde ${ }^{1}$, K.G. Patel ${ }^{2}$ and Shailesh Tayade ${ }^{3}$ \\ 1,3 ( Ph.D Scholars, Deptt. of Entomology, N.M. College of Agriculture, N.A.U., Navsari-396 450, Gujarat, India) \\ ${ }^{2}$ (Principal, college of Agriculture, N.A.U., Bharuch-392 001, Gujarat, India)
}

\begin{abstract}
Life table study is very useful to analyse the mortality of insect population, to determine key factors responsible for the highest mortality within population. It is determined by two types viz., Age Specific (or Horizontal) and Stage Specific (or Vertical) Life Table. Moreover, various mathematical formulas also indicated for the appropriate evaluation of life fecundity tables, stable age distribution and life expectancy. Life expectancy of beneficial insects can be calculated and used for biological control program by predicting natural things in particular instar within which the maximum mortality of the pests is obtained and plan for managing pests in time.
\end{abstract}

Keywords: Life table, Insect pests, Life fecundity, Life expectancy

\section{Introduction}

A life table is a kind of book-keeping system that ecologists often used to keep track of stage specific mortality in the population they study. A life describes for successive age intervals, the number of deaths, the survivors, the rate of mortality and the expectation of further life. Life table provides an important tool in understanding the changes in population of insect pests during different developmental stages throughout their life cycle. It is an especially useful approach in entomology, where developmental stages are discrete and mortality rates may vary widely from one life stage to another. It is very useful to analyze the mortality of insect population to determine key factors responsible for the highest mortality within population. The construction of several life tables may be possible to prepare a predictive model which can be tested against natural population fluctuations. Life table is an important analytical technique in studying distribution, determination of age and mortality of an organism and individuals can be calculated.

\section{Nature And Origin}

Leopold was the first researcher to identify the value of the life table in the study of natural population and he called it as "Life equation" (Harcourt, 1969). Morris and Miller (1954) presented the first detailed example of a life table for natural population of spruce budworm.

\section{Types Of Life Table}

1. Age Specific (or Horizontal) Life Table: It is based on the fate of a real cohort, conveniently the members of a population belonging to a single generation and of same age. The population may be stationary or fluctuating.

2. Stage Specific (or Vertical) Life Table: It is based on the fate of an imaginary cohort found by determining the age structure. Here population remains stationary with considerable overlapping of generations.

According to Hasan and Ansari (2009), age specific survivorship (lx) of Earias vitella (Fabricius) decreased from $1^{\text {st }}$ to $10^{\text {th }}$ day while, survivorship was greatly reduced on the $38^{\text {th }}$ day whereas the highest mortality (dx) was noticed on the $36^{\text {th }}$ day $(15 \%)$ and on the basis of stage specific life table, the apparent mortality (100qx) of eggs were calculated (16\%).

\section{Life fecundity tables}

Hemchandra and Singh (2003) reported that pre-oviposition period of Plutella xylostella (Linnaeus) was on $21^{\text {st }}$ day of pivotal age and the female contributed the highest number of progeny $(\mathrm{mx}=70.013$ females/female/day) in the life cycle during $24^{\text {th }}$ day of pivotal age. Arshad and Rizvi (2007) revealed that immature stages and pre-ovipositional period of Coccinella septempunctata L. on different aphid species and observed maximum on Macrosiphum rosae L. (0.5 to 39.5 days) and minimum on Aphis craccivora (K.) (0.5 to 30.5 days ) and also found that $C$. septempunctata produced maximum offspring on Lipaphis erysimi (K.) and minimum on M. rossae. Gedia et al. (2008a) studied the life fecundity data of Spodoptera litura (Fabricius) on cotton and indicated that pre-oviposition period ranged from $35^{\text {th }}$ to $36^{\text {th }}$ day of pivotal age and the female contributed the highest number of progeny ( $\mathrm{mx}=104.90$ females/female/day) in the life cycle during $39^{\text {th }}$ day of pivotal age also Gedia et al. (2008b) studied the life fecundity data of $S$. litura on groundnut and indicated that 
pre-oviposition period ranged from $31^{\text {st }}$ to $32^{\text {nd }}$ day of pivotal age and the female contributed the highest number of progeny ( $\mathrm{mx}=172.04$ females/female/day) in the life cycle during $35^{\text {th }}$ day of pivotal age. According to Jethva and Vyas (2009), life fecundity data of Leucinodes orbanalis (Guenee) indicated that pre-oviposition period ranged from $34^{\text {th }}$ to $35^{\text {th }}$ day of pivotal age and the female contributed the highest number of progeny $(\mathrm{mx}=80.20 \mathrm{females} / \mathrm{female} /$ day $)$ in the life cycle during $39^{\text {th }}$ day of pivotal age.

\section{Mean length of generation (Tc), Innate capacity for increase in numbers (rm), Finite rate of natural increase $(\lambda)$}

1. Mean length of generation (Tc)

The approximate value of generation time (Tc) (the mean age of the mothers in a cohort at the birth of female offspring) was calculated with the help of following formula:

$$
\text { Tc }=\text { = }
$$

Ro

2. Innate capacity for increase in numbers (rm)

Total number of individual survived and mean number of female offsprings birth was recorded at each age interval. From these data the arbitrary values of 'rm' was derived by using the following formula:

\section{$\log _{\mathrm{e}}$ Ro}

$\mathbf{r m}$

$$
\text { Tc }
$$

Where,

$\mathrm{Tc}=$ Mean generation time

The intrinsic rate of increase ( $\mathrm{rm}$ ) was subsequently calculated from arbitrary ' $\mathrm{rm}$ ' by establishing the following relationship (Atwal and Bains, 1974 ),

$\sum \mathbf{e}^{7-r m x} . \mathbf{L x m x}$

The precise generation time $(\mathrm{T})$ was then calculated by using formula: $\log _{\mathrm{e}} \mathbf{R}$

$\mathbf{T}=\mathbf{r m}$

3. The finite rate of increase in number $(\lambda)$

The number of female per female per day i.e., finite rate of increase was determined as: $\lambda=$ Antilog $\mathrm{e}^{\mathrm{rm}}$

Acharya et al. (2007) calculated mean length of generation (Tc), innate capacity for increase in number $(\mathrm{rm})$ and finite rate of natural increase $(\lambda)$ of Helicoverpa armigera (Hubner) to the tune of 42.99 day, 0.1379 females/female/day and 1.1489 females/female/day, respectively. Arshad and Rizvi (2007) studied the summary of life parameters of $C$. septempunctata on different aphid species and found that A.craccivora and L. erysimi showed the minimum generation period, doubling time and maximum annual rate of increase.

\section{Stable age distribution}

The stable age distribution is the age distribution which would be approached by a population of stable age-schedule of birth-rate and death-rate (i.e., ' $m x$ ' and ' $1 \mathrm{x}$ ' are constant). The stable age distribution table was constructed by following the method of Atwal and Bains (1974). The 'Lx' was calculated from the 'lx' table by using the following formula:

$$
\mathbf{L x}=\mathbf{l x}+(\mathbf{l x}+\mathbf{1})
$$

Hemchandra and Singh (2003) reported that the maximum distribution of the population of $P$. xylostella was made by egg, larva, pre-pupa, pupa and adult was $51.34,39.86,2.27,3.14$ and 3.19 per cent, respectively. Acharya et al. (2007) showed that the maximum distribution of the population of $H$. armigera was made by larva, egg, pupa and adult was 51.1, 43.7, 4.7 and 0.4 per cent, respectively. According to Shah et al. (2007) the maximum distribution of the population of A. gossypii made by nymphs and adults was 89.93 and 10.07 per cent, respectively, whereas Gedia et al. (2008b) studied that the maximum distribution of the population of S.litura on groundnut was made by egg, larva, pupa and adult was 52.00, 46.40, 1.30 and0.30 per cent, respectively. 


\section{Life expectancy}

Life expectancy on different hosts was worked out by using columns x, 1x, dx, 100qx, Lx, Tx and ex.

$$
\text { dx. } 100
$$

$100 q x=-\cdot-\cdot-\cdot$

Mortality rate per hundred alive at beginning of age interval.

Where,

$\mathrm{x}=$ Pivotal age (days)

$\mathrm{lx}=$ The number surviving at the beginning of age interval out of 100 .

$\mathrm{dx}=$ number of dying during ' $\mathrm{x}$ '.

$$
L x=\frac{1 x+(l x+1)}{2}
$$

Alive between $\mathrm{x}$ and $\mathrm{x}+1$

$\mathrm{Tx}=$ Number of individual's life day beyond $\mathrm{x}$.

$\mathrm{ex}=(\mathrm{Tx} / \mathrm{lx} \mathrm{x} 2)$ Expectation of further life.

Gedia et al. (2008a) revealed that life expectancy of newly deposited eggs of S.litura on cotton was 15.58 days while, mortality rate of was comparatively high during the age of 40 to 45 days, when the expectation of further life was reduced only to 2.79 days from 15.58 days in the beginning whereas Jethva and Vyas (2009) reported that life expectancy of newly deposited eggs of L.orbanalis was 14.26 days while, mortality rate was comparatively high during the age of 40 to 45 days, when the expectation of further life was reduced only to 1.61 days from 14.26 days in the beginning.

\section{Criteria for filling the columns of life table}

\section{Construction Of Life Tables For Study Of Field Population}

Harcourt (1969) proposed the criteria for filling the data in the life table for each age interval (stage).

Eggs: In case of eggs, ' $\mathrm{x}$ ' is based on direct sampling of the population at the completion of oviposition. The ' $\mathrm{dx}$ ' value is obtained from the percentage found to be infertile.

Early instar larvae: The ' $\mathrm{x}$ ' for early instar larvae is obtained by direct sampling of the quadrates in the field and computed on hectare basis.

Late instar larvae: The ' $1 \mathrm{x}$ ' is obtained by deducting the mortality of larvae due to the parasitoid and unknown causes from the early instar.

Pupae: The ' $\mathrm{x}$ ' is determined after subtracting the mortality of late instar larvae due to parasitoids and unknown causes.

Adults: This ' $1 \mathrm{x}$ ' represents the number of pupae giving to adults. The mortality in the pupal stage due to parasitoids and unknown causes is subtracted from the ' $1 \mathrm{x}$ ' of pupae and thus, the ' $\mathrm{l} x$ ' value for adults were determined for all practical purpose.

Trend index: This was simply ' $\mathrm{l} x$ ' for the early instars larvae in the next generation expressed as a ratio of previous generation.

Trend index $=\mathrm{N}_{2} / \mathrm{N}_{1}$

Where,

$\mathrm{N}_{2}=$ Population of larvae in next generation

$\mathrm{N}_{1}=$ Population of larvae in previous generation. mortality.

Generation survival: This was index of population trend without the effect of fecundity and adult

Generation survival $(\mathrm{SG})=\mathrm{N}_{3} / \mathrm{N}_{1}$

Where,

$\mathrm{N}_{3}=$ Population of adults in a generation

$\mathrm{N}_{1}=$ Population of larvae in the same generation.

K - Value: It is a key factor which is primarily responsible for increase or decrease in number from one generation to another and was computed as difference between successive values for log ' $1 \mathrm{x}$ '. However, the total generation mortality was calculated by adding ' $\mathrm{K}$ ' values of different development stages or the insect which is indicated as ' $\mathrm{K}$ '.

$$
\mathrm{K}=\mathrm{k}_{\mathrm{E}}+\mathrm{k}_{\mathrm{L} 1}+\mathrm{k}_{\mathrm{L} 2}+\mathrm{k}_{\mathrm{L} 3}+\mathrm{k}_{\mathrm{L} 4}+\mathrm{kpp}+\mathrm{kp}
$$

Where, $\mathrm{k}_{\mathrm{E}}, \mathrm{k}_{\mathrm{L} 1}, \mathrm{k}_{\mathrm{L} 2}, \mathrm{k}_{\mathrm{L} 3}, \mathrm{k}_{\mathrm{L} 4}$, $\mathrm{kpp}$, $\mathrm{kp}$ are the ' $\mathrm{K}$ ' values at egg, first instar, second instar, third instar, fourth instar, prepupal and pupal stage.

Jagtap et al.(2007) studied only one generation of Trichoplusia ni (Hubner) on okra and reported that 
mortality factors in different stages were identified as unknown factors, white muscardine fungus, Apanteles sp., green muscardine fungus and Euplectrus sp. While the same procedure was carried out on S.litura on okra. Sugawe and Bilapate (2007) studied the two generation of Helicoverpa armigera (Hubner) on arhar during 2004-05. During $1^{\text {st }}$ generation the mortality factors in different stages were identified as sterility, Campoletis chlorideae U., NPV, un identified fungus, unknown reason and Goniophthalmus halli $\mathrm{M}$. Whereas, $2^{\text {nd }}$ generation revealed that mortality factors in different stages were identified as sterility NPV and unknown reason.

\section{Life Table In Pest Management}

The life tables provide a way to tabulate birth and death of insects. With the help of life tables, we can calculate the life expectancy of beneficial insects and can be used for the biological control by predicting natural things in particular instar within which we get maximum mortality. On this basis, we can prepare a plan for the management of insect pest at particular time. Key factor analysis has proven to be a valuable aid in identifying the environmental factors most closely related to intergenerational population trend. Life tables have been prepared for several insect pests in India viz., H. armigera, S. litura, etc. and key mortality factors have been identified.

\section{Conclusion}

Construction of life tables is an important tool for understanding the population dynamics of an insect. It serves as a framework for organizing dates on mortality and natality. It generates simple summary statistics such as life expectancy and reproduction rate. From a pest management standpoint, it is very useful to know when (and why) a pest population suffers high mortality. This is usually the time, when it is the most vulnerable. By knowing such vulnerable stages from life table, we can make time based application of insecticide for the management of insect pests, to conserve the natural parasites and predators and to reduce the environmental pollution.

\section{References}

[1] D. G. Harcourt, The development and use of life tables in the study of natural insect populations, Annual Review of Entomology, 14,1969,175-196.

[2] R. F. Morris and C. A. Miller, The development of life tables for the spruce budworm. Canadian Journal of Zoology, 32, 1954, 283-301.

[3] W. Hasan and M. S. Ansari, Life Table of Spotted Bollworm, Earias vitella on Okra, Annals of Plant Protection Sciences, 17, 2009, 86-89.

[4] O. Hemchandra and T. K. Singh, Life Table, Rate of Increase and Stable-age Distribution of Plutella xylostella (Linnaeus) on Cauliflower Annals of Plant Protection Sciences, 11, 2003, 269-273.

[5] A. Arshad and P. Q. Rizvi, Age specific Survival and Fecundity Table of Coccinella septumpunctata L. on different Aphid species, Annals of Plant Protection Sciences, 15 (2), 2007, 329-334.

[6] M. V. Gedia, H. J. Vyas, M. F. Acharya and P. V. Patel, Life table, Rate of Increase and Stable Age Distribution of Spodoptera litura (Fabricius) on cotton, Annals of Plant Protection Sciences, 16(1), 2008a, 62-65.

[7] M. V. Gedia, H. J. Vyas, M. F. Acharya and P. V. Patel, Studies on Life fecundity Tables of Spodoptera litura (Fabricius) on Groundnut, Annals of Plant Protection Sciences, 16(1), 2008b, 74-77.

[8] D. M. Jethva and H. J. Vyas , Studies on Life fecundity Tables of Leucinodes orbonalis Guenee on Brinjal, Annals of Plant Protection Sciences, 17, 2009, 346-350.

[9] A. S. Atwal and S. S. Bains, Physical environment, Applied Animal Ecology (Kalyani Publishers, Ludhiana, 1974) 11-35.

[10] M. F. Acharya, H. J. Vyas, M. V. Gedia and P. V. Patel, Life table, Intrinsic rate of Increase and Age-specific Distribution of Helicoverpa armigera (Hubner) on Cotton, Annals of Plant Protection Sciences, 15 (2), 2007, 338-341.

[11] M. A. Shah, T.K. Singh and G.K. Chhetry, Life table, stable age, distribution and life expectancy of Aphis gossypii Glover on okra, Annals of Plant Protection Sciences, 15, 2007, 57-60.

[12] C. R. Jagtap, S. S. Shetgar and P. K. Nalwandikar, LIFE-TABLE AND KEY MORTALITY FACTORS OF LEPIDOPTEROUS FOLIAGE PESTS OF OKRA, Indian Journal of Entomology, 69, 2007, 311-314.

[13] A. G. Sugawe and G.G. Bilapate, Field Life-table and Key Mortality Factors of Major Lepidopteran Pod Borers on Arhar, Journal of Maharashtra Agricultural University, 32(3), 2007, 361-364. 